Br Heart J 1989;61:9-13

\title{
Review
}

\section{Treatment of pain in acute myocardial infarction}

\author{
JOHAN HERLITZ, ÅKE HJALMARSON, FINN WAAGSTEIN \\ From the Department of Medicine I, Sahlgren's Hospital, University of Gothenburg, Gothenburg, Sweden
}

SUMMARY The treatment of pain in acute myocardial infarction varies with local practice. Narcotic analgesics are still the usual treatment in many hospitals. Knowledge of optimal doses, duration of pain relief, and time between drug administration and pain relief is inadequate. Many studies indicate that the relief of pain is often incomplete after treatment with narcotic analgesics. There is often a need for alternative treatments. Large randomised studies consistently show that $\beta$ blockade, initially given intravenously and then orally, relieves pain and reduces the need for analgesics. Studies also indicate that early administration of streptokinase and glyceryl trinitrate relieves pain. There is evidence that drugs that limit ischaemic damage also relieve pain.

Chest pain is the most obvious clinical marker of myocardial ischaemia in the acute phase of a suspected acute myocardial infarction. Pain relief is important, not only for patient well being, but also because pain can induce systemic circulatory effects such as an increase in blood pressure, heart rate, and stroke volume. These changes may adversely influence the balance between myocardial metabolic requirement and supply and result in infarct extension. Various treatments have been suggested ranging from pure analgesics, particularly narcotics or tranquillisers, to drugs that have a direct or indirect effect on the ischaemic myocardium. ${ }^{1-3}$

\section{Narcotic analgesics}

DRUGS

The most commonly used agents are morphine, pethidine, pentazocine, methadone, and diamorphine (heroin). Morphine and diamorphine are the most popular because they have been more extensively studied and have better haemodynamic effects than, for example, pentazocine.

\section{RELIEF OF PAIN}

The analgesic effect is said to be the result of an increased pain threshold and a reduced sympathetico-adrenal response. Relief of pain in suspected acute myocardial infarction varies considerably. The results depend on how soon after the injection pain

Requests for reprints to Dr Johan Herlitz, Department of Medicine I, Sahlgren's Hospital, S-8413 45 Gothenburg, Sweden.

Accepted for publication 12 August 1988 relief is assessed. Since the pain course is difficult to predict, it is difficult to assess whether or not relief or complete disappearance of pain is the result of drug administration. It is said that in many patients relief of pain is unsatisfactory after the administration of morphine $e^{4-6}$ and that narcotics rarely give complete pain relief. ${ }^{4}$

DELAY UNTIL OPTIMAL ANALGESIA

The time lag from drug administration until optimal relief of pain has not been comprehensively assessed. A delay of 20 minutes was reported after intravenous administration and 45-90 minutes after intramuscular administration of analgesics. ${ }^{89}$ It is likely that diamorphine and maybe also methadone act somewhat faster than morphine. ${ }^{410}$ The effect of diamorphine may be more rapid because it is more soluble in water and so it reaches the circulation more quickly. Its active metabolite, 6-monoacetylmorphine, also quickly passes the blood-brain barrier.

\section{DURATION OF ANALGESIA}

The duration of analgesia is difficult to estimate because of the large variability in the course of pain. ${ }^{112}$ Postoperative studies suggest that analgesia is effective for seven and nine hours after the administration of 10 and $15 \mathrm{mg}$ morphine respectively. ${ }^{13}$

\section{OPTIMAL DOSES}

Little is known about the optimal doses of narcotic analgesics in suspected acute myocardial infarction. Other clinical applications indicate that $7-9 \mathrm{mg}$ of 
morphine $/ 70 \mathrm{~kg}$ is optimal and that any further dose increase does not produce greater relief of pain..$^{13}$ In one study $15 \mathrm{mg}$ of morphine given postoperatively resulted in effective pain relief in $83 \%$ of patients, whereas $10 \mathrm{mg}$ produced relief in $74 \% .{ }^{13}$ Any evaluation of optimal doses of narcotic analgesics must take account of the side effects.

\section{SIDE EFFECTS}

Circulatory

When morphine is given to patients who are standing or sitting it induces a drop in blood pressure, most probably by dilatating the capacitance vessels. The unfavourable cardiovascular effects of morphine have been explained by activation of the parasympathetic nervous system. Previously it was suggested that morphine could induce severe hypotension in a high proportion of patients with acute myocardial infarction. ${ }^{14}$ But studies showed a significant drop in blood pressure with or without an increase in heart rate in $2-8 \% .{ }^{15} 16$ Hypotension has not been shown to be associated with infarct site. ${ }^{16}$

Unlike morphine, pentazocine increases the systemic and pulmonary artery pressures, left ventricular filling pressure, systemic vascular resistance, and systolic and diastolic heart volumes and decreases the ejection fraction. ${ }^{17}$ Morphine, therefore, seems to protect the myocardium more than pentazocine.

\section{Respiratory \\ Morphine, diamorphine, pethidine, and pentazocine all induce moderate respiratory changes in acute myocardial infarction including a marginal decrease in $\mathrm{pO}_{2}$ and a marginal increase in $\mathrm{pCO}_{2} \cdot{ }^{10} \mathrm{It}$ has been suggested that diamorphine induces a more rapid but not more pronounced increase in $\mathrm{pCO}_{2}$ and a more pronounced decrease in $\mathrm{pO}_{2}$ than morphine. Res- piratory insufficiency seems to be rare after treatment with narcotic analgesics in acute myocardial infarc- tion. There was respiratory failure in $1 \%$ of patients given morphine and $3 \%$ of patients given pethidine in acute myocardial infarction. ${ }^{15}$}

\section{Cenitral nervous system}

Nausea was reported in $20-30 \%$ of patients given morphine or pethidine ${ }^{15}$ and $5-15 \%$ of patients treated with narcotic analgesics vomited..$^{15}$ Vertigo occurred in $10-30 \%$ of patients. ${ }^{15}$ All these symptoms are common in acute myocardial infarction and it is difficult to assess their association with drug treatment.

\section{$\beta$ Blockers}

It is more than 10 years since the first report that intravenous administration of $\beta$ blockers to selected patients in the early phase of acute myocardial infarction relieved pain within a few minutes, an effect that persisted for the first hour. In a placebo controlled study by Waagstein and Hjalmarson of practolol, H 87/07 (AB Hässle, Mölndal, Sweden) and metoprolol, three selective blockers two of which (H 87/07 and practolol) had intrinsic stimulatory activity, pain relief occurred within two minutes and the maximum effect was observed within five minutes of the end of intravenous injection. Ten minutes after injection $\mathbf{7 0} \%$ had satisfactory pain relief and after one hour $50 \%$ had satisfactory pain relief. Metoprolol (with no intrinsic stimulatory activity) had the most pronounced effect on pain and on heart work. The effect was similar irrespective of whether the infarction was transmural or subendocardial. ${ }^{2}$

These initial observations have been confirmed in large randomised studies in which more representative patient populations have been studied. Intravenous administration of different $\beta$ blockers such as propranolol, atenolol, metoprolol, and timolol reduces the pain early,,$^{19-22}$ and consumption of analgesics indicates that symptoms of pain are reduced during the next few days if early intravenous treatment is followed by oral treatment. ${ }^{202324}$ In the Göteborg Metoprolol Study of 1395 patients the requirement for analgesics was reduced by $30 \%$ during the first four days in the coronary care unit. ${ }^{23}$ Similar results were reported by Ramsdale $e t$ al in a study including 78 patients with suspected acute myocardial infarction. ${ }^{20}$ Of those who received atenolol intravenously followed by oral treatment, $60 \%$ required narcotic analgesics during the next 24 hours compared with $77 \%$ of patients given placebo.

In the Metoprolol in Acute Myocardial Infarction on (MIAMI) Trial which included 5778 patients randomised to either metoprolol or placebo treatment, ${ }^{24}$ the estimated number of hours of pain was reduced by $17 \%$. The number of patients with severe chest pain (defined as pain requiring at least four injections of narcotic analgesics in combination with glyceryl trinitrate and calcium antagonist) was reduced by $42 \%$ in the metoprolol group.

\section{SUBGROUP ANALYSIS}

In two metoprolol studies the authors assessed the distribution of pain relief in different subgroups. ${ }^{23}{ }^{24}$ In both the effect was most pronounced in patients with a high initial rate-pressure product. In patients with either a low initial systolic blood pressure $(<120 \mathrm{~mm} \mathrm{Hg})$ or a low initial heart rate $(<60$ beats/ min) the pain course was similar in patients given metoprolol and placebo, as judged by their requirement for analgesics. To some extent this explains why relief of chest pain was better in patients with anterior infarction than in those with inferior infarction. ${ }^{2324}$ The patients' requirement for analgesics was reduced to a similar extent both in the study in which metoprolol was started very early and in the study in which it was started later. 
MECHANISMS OF THE PAIN RELIEVING EFFECT OF $\beta$ BLOCKADE

There are several possible explanations for the pain relief produced by $\beta$ blockade in suspected acute myocardial infarction. A reduction in heart work (reduced heart rate, systolic blood pressure, and contractility) improves the relation between coronary perfusion (access of oxygen and nutrients and washout of metabolites) and the myocardial metabolic demand.

A reduction in myocardial metabolic demand reduces the requirement for coronary flow in normal areas, which may cause redistribution of flow to ischaemic areas. In addition, a reduced heart rate prolongs the diastolic perfusion period. In experimental studies in animals, propranolol and metoprolol increased collateral circulation to the ischaemic myocardium. ${ }^{25-27}$

Since it is thought that pain comes only from an ischaemic myocardium, one hypothesis is that pain relief is promoted by reduced ischaemia. The reduction in ST elevation and the rate-pressure product, which were seen in association with pain relief, supports this hypothesis. However, the relation between the decrease in rate-pressure product and the relief of pain after administration of $\beta$ blockade is not always close. Such observations were reported in angina pectoris and myocardial infarction. ${ }^{2028}$ Morphine, however, reduces chest pain without changing the level of the ST segment elevation in acute myocardial infarction. ${ }^{2}$

\section{SIDE EFFECTS}

Tolerance of $\beta$ blockade in suspected acute myocardial infarction has been evaluated extensively in patients with uncomplicated myocardial infarction ${ }^{29}$ as well as in a more representative patient series. ${ }^{30-32}$ Taking into account the well known cardiovascular contraindications of hypotension, bradycardia, atrioventricular block, severe left heart failure and severe asthma, tolerance was good. On the basis of previous experiences, it seems that about $80 \%$ of patients admitted to the coronary care unit because of suspected açute myocardial infarction can be given $\beta$ blockade in the acute phase. The remaining $20 \%$ have absolute contraindications.

\section{OPTIMAL DOSES}

The optimal doses of those $\beta$ blockers that have been evaluated for pain relief in suspected acute myocardial infarction are not yet known. At present, we can only examine the doses used in reported studies. It is possible that many patients who are already receiving long term treatment with $\beta$ blockers will require higher doses than previously untreated patients because of down regulation of the $\beta$ receptor.
It may be more appropriate to adjust individual dosage according to heart rate and systolic blood pressure.

\section{Glyceryl trinitrate}

It is generally accepted that glyceryl trinitrate administered in the early phase of acute myocardial infarction gives pain relief. The objective evidence for this, however, is not conclusive. The pain relief obtained with repeated sublingual doses of glyceryl trinitrate was compared with that obtained with morphine in 30 patients with acute myocardial infarction. ${ }^{3}$ Thirteen of 15 patients who received glyceryl trinitrate were free from pain within two hours compared with all of 15 patients receiving morphine. In another study of 30 patients with acute myocardial infarction, intravenous infusion of glyceryl trinitrate gave initial pain relief but the longer term requirement for analgesics was not reduced..$^{33}$ In contrast, treatment with intravenous glyceryl trinitrate is known to relieve pain in patients with unstable angina pectoris. ${ }^{33}{ }^{34}$ In a study of 35 patients, all of whom had angina pectoris at rest which was not responding to $\beta$ blockers or transdermal or oral glyceryl trinitrate, intravenous infusion of glyceryl trinitrate reduced the mean (SD) number of angina attacks per day from $3.5(0.4)$ to 0.3 $(0 \cdot 1)$ and correspondingly reduced the requirement for sublingual glyceryl trinitrate and for morphine. ${ }^{34}$

\section{Other treatment alternatives}

\section{THROMBOLYSIS}

Despite the fact that thrombolytic treatment has been reported to restore blood flow to the ischaemic myocardium there is little information about its effects on pain in the acute phase. Pain relief was reported in one study after early thrombolysis. ${ }^{35}$ It may be that early thrombolysis gives considerable pain relief in some patients but its effects must be assessed more systematically.

\section{SEDATIVES}

It has been reported that levomepromazine has a similar analgesic effect to that of pethidine but with fewer side effects. ${ }^{1}$ Mortality over four weeks and one year was significantly lower in patients given levomepromazine than in those treated with pethidine. $^{1}$

\section{ANTI-INFLAMMATORY DRUGS}

Anti-inflammatory drugs are well tolerated in acute myocardial infarction and do not induce important haemodynamic changes. ${ }^{6}$ Intravenous indoprofen (400 mg) gave better pain relief than intramuscular morphine $(10 \mathrm{mg}){ }^{6}$ 


\section{NITROUS OXIDE}

Nitrous oxide $(35 \%)$ relieved angina. ${ }^{36}$ Complete relief of pain was reported in $39 \%$ of patients, but the effect was most impressive in patients with mild chest pain. The dose was well tolerated and there were no haemodynamic changes. In Britain, Entonox, a mixture of $50 \%$ nitrous oxide with oxygen, is widely used in the ambulance service. ${ }^{37}$

\section{EPIDURAL AND INTRATHECAL ANAESTHESIA}

Intrathecal morphine was effective, with a rapid onset of action and few or no side effects. ${ }^{38}{ }^{39}$ Epidural administration of morphine was effective in patients in whom intravenous morphine was unsuccessful..$^{40}$

Thoracic epidural sympathetic blockade gave effective pain relief in unstable angina. ${ }^{42}$ Evaluation in acute myocardial infarction is limited.

\section{Patient controlled analgesia}

It can be difficult for others to assess a patient's requirement for pain relief. Patient controlled analgesia is most commonly used after operation ${ }^{43}$ and during child birth." When the patient presses a button a limited amount of morphine, for example, is infused over a certain interval. The infusion intervals are adjusted for dose, and the patient's age and body weight. This type of treatment has been only occasionally evaluated in acute myocardial infarction:

\section{Optimal use of analgesics}

In the coronary care units in Sweden pain relief is usually given by nurses. Their assessment of the severity of pain will determine whether the patient is adequately treated. Bondestam et al compared nurses' assessment of pain with that of 47 patients with acute myocardial infarction. ${ }^{7}$ There was a positive correlation between the nurses' and the patients' estimations ( $f=0.76 ; p<0.001$ ). The nurses underestimated the patient's pain on $23 \%$ of occasions and overestimated it in $20 \%$. Overestimation was more common at higher heart rates and blood pressures. This study also found that patients who said that they had severe pain were not always given pain relief.

\section{Clinical implications}

We believe that the initial treatment of pain in acute myocardial infarction should be based on antiischaemic drugs.

Patients who present soon after the onset of pain with the electrocardiographic changes of acute infarction, should be given immediate thrombolytic treatment if there are no contraindications. We think that $\beta$ blockers should also be given promptly to suitable patients in whom the heart rate is $>50-60$ beats/min. Although such treatment will reduce pain in many patients, the effect is unpredictable and narcotic analgesics should be given quickly if necessary. We cannot be certain how well patients will tolerate such a combination of treatment but we can recommend it provided there is careful monitoring of the heart rate and systolic blood pressure. If pain continues, a glyceryl trinitrate infusion should probably be started. Subsequent treatment depends on local experience. More experience of the effect of anti-inflammatory drugs, sedatives, and epidural anaesthesics is needed before these alternatives can be widely recommended.

\section{Future aspects}

Narcotic analgesics such as morphine will remain the first line treatment of severe pain in acute myocardial infarction, but drugs with a more rapid effect that give better pain relief need to be developed. This in combination with the development of anti-ischaemic drugs should improve the treatment of pain in suspected acute myocardial infarction. Because pain is most intense in the early phase ${ }^{45}$ treatment should be started before the patient is admitted to hospital.

\section{References}

1 Davidsen O, Lindeneg O, Walsh M. Analgesic treatment with levomepromazine in acute myocardial infarction. Acta Med Scand 1979;205:191-4.

2 Waagstein F, Hjalmarson $\AA$. Double-blind study of the effect of cardioselective beta-blockade on chest pain in acute myocardial infarction. Acta Med Scand 1975;suppl 587:201-8.

3 Lis Y, Bennett D, Lambert G, Robson D. A preliminary double-blind study of intravenous nitroglycerin in acute myocardial infarction. Intensive Care Med 1984;10:179-84.

4 Scott ME, Orr R. Effects of diamorphine, methadone, morphine, and pentazocine in patients with suspected acute myocardial infarction. Lancet 1969;i:1065-7.

5 Hayes MJ, Fraser AR, Hampton JR. Randomised trial comparing buprenorphine and diamorphine for chest pain in suspected acute myocardial infarction. Br Med J 1979;ii:300-2.

6 Bressan MA, Costantini M, Klersy C, et al. Analgesic treatment in acute myocardial infarction: a comparison between indoprofen and morphine by a doubleblind randomized pilot study. Int J Clin Pharmacol Ther Toxicol 1985;23:668-72.

7 Bondestam E, Hovgren K, Gaston Johansson F, Jern S, Herlitz J, Holmberg S. Pain assessment by patients and nurses in the early phase of acute myocardial infarction. $J$ Adv Nurs 1987;12:677-82.

8 Todres D. The role of morphine in acute myocardial infarction. Am Heart $J$ 1971;81:566-70.

9 Alderman EL. Analgesics in the acute phase of myocar- 
dial infarction. JAMA 1974;229:1646-8.

10 Kerr F, Donald KW. Analgesia in myocardial infarction. Br Heart $J$ 1974;36:117-21.

11 Herlitz J, Hjalmarson A, Holmberg S, et al. Variability, prediction and prognostic significance of chest pain in acute myocardial infarction. Cardiology 1986;73: 13-21.

12 Herlitz J, Richter A, Hjalmarson $\AA$, et al. Variability of chest pain in suspected acute myocardial infarction according to subjective assessment and requirement of narcotic analgesics. Int J Cardiol 1986;13:9-22.

13 Lasagna L, Beecher HK. The optimal dose of morphine. JAMA 1954;156:230-4.

14 Thomas M, Malmcrona R, Fillmore S, Shillingford J. Haemodynamic effects of morphine in patients with acute myocardial infarction. Br Heart $J$ 1965;27: 863-75.

15 Nielsen JR, Pedersen KE, Dahlström CG, et al. Analgetic treatment in acute myocardial infarction. A controlled clinical comparison of morphine, nicomorphine and pethidine. Acta Med Scand 1984;215: 349-54.

16 Semenkovich CF, Jaffe AS. Adverse effects due to morphine sulfate. Challenge to previous clinical doctrine. Am J Med 1985;79:325-30.

17 Alderman EL, Barry WH, Graham AF, Harrison DC. Hemodynamic effects of morphine and pentazocine differ in cardiac patients. $N$ Engl $J$ Med 1972;287: 623-7.

18 Lee G, DeMaria AN, Amsterdam EA, et al. Comparative effects of morphine, meperidine and pentazocine on cardiocirculatory dynamics in patients with acute myocardial infarction. $\mathrm{Am} J \mathrm{Med}$ 1976;60:949-55.

19 Gold HK, Leinbach RC, Maroko PR. Propranololinduced reduction of signs of ischemic injury during acute myocardial infarction. $\mathrm{Am} J$ Cardiol 1976;38:689-95.

20 Ramsdale DR, Faragher EB, Bennett DH, et al. Ischemic pain relief in patients with acute myocardial infarction by intravenous atenolol. Am Heart $J$ 1982;103:459-67.

21 Richterova A, Herlitz J, Holmberg S, et al. Effects on chest pain. Am J Cardiol 1984;53:32D-6D.

22 The International Collaborative Study Group. Reduction of infarct size with the early use of timolol in acute myocardial infarction. $N$ Engl J Med 1984;310:9-15.

23 Herlitz J, Hjalmarson $\AA$, Holmberg S, et al. Effect of metoprolol on chest pain in acute myocardial infarction. Br Heart J 1984;51:438-44.

24 The MIAMI Trial Research Group. Narcotic analgesics and other antianginal drugs. Am J Cardiol 1985;56:30G-4G.

25 Vatner SF, Baig H, Manders WT, et al. Effects of propranolol on regional myocardial function, electrograms and blood flow in conscious dogs with myocardial ischaemia. J Clin Invest 1977;60:353-60.

26 Becker LC, Fortuin NJ, Pett B. Effect of ischemia and antianginal drugs on the distribution of radioactive microspheres in the canine left ventricle. Circ Res 1971;28:263-9.

27 Buck JD, Hardman HF, Warltier DC, Gross GJ. Changes in ischemic blood flow distribution and dynamic severity of a coronary stenosis induced by beta blockade in the canine heart. Circulation 1981;64:708-15.

28 Jackson G, Atkinson L, Orarn S. Reassessment of failed beta-blocker treatment in angina pectoris by peakexercise heart rate measurements. $\mathrm{Br} \mathrm{Med} J$ 1975;ili:616-8.

29 Málek I, Waagstein F, Hjalmarson $\AA$, et al. Hemodynamic effects of the cardioselective beta-blocking agent metoprolol in acute myocardial infarction. Acta Med Scand 1978;204:195-201.

30 Herlitz J, Pennert K, Wedel H, et al. Tolerance. Am J Cardiol 1984;53:46D-50D.

31 The MIAMI Trial Research Group. Other clinical findings and tolerability. Am J Cardiol 1985;56: 39G-46G.

32 ISIS-1 Collaborative Group. A randomised trial of intravenous atenolol among 16027 cases of suspected acute myocardial infarction. Lancet 1986;ii:57-66.

33 Mikolich JR, Nicoloff NB, Robinson PH, Logue RB. Relief of refractory angina with continuous intravenous infusion of nitroglycerin. Chest 1980;77:375-9.

34 Kaplan K, Davidsson R, Parker M, et al. Intravenous nitroglycerin for the treatment of angina at rest unresponsive to standard nitrate therapy. Am J Cardiol 1983;51:694-8.

35 Anderson JL, Marshall HW, Askins JC, et al. A randomized trial of intravenous and intracoronary streptokinase in patients with acute myocardial infarction. Circulation 1984;70:606-18.

36 Thompson PL, Lown B. Nitrous oxide as an analgesic in acute myocardial infarction. JAMA 1976;325: 924-7.

37 Kerr F, Hoskins DJ, Brown MG, Ewing DJ, Irving JB, Kirby BJ. A double-blind trial of patient-controlled nitrous-oxide/oxygen analgesia in myocardial infarction. Lancet 1975;i:1397-400.

38 Pasqualucci V. Advances in the management of cardiac pain. Adv Pain Res Ther 1984;7:501-4.

39 Pasqualucci V, Moricca G, Solinas P. Intrathecal morphine for the control of the pain of myocardial infarction. Anaesthesia 1981;36:68-9.

40 Behar M, Magora F, Olshwang D, Davidsson JT. Epidural morphine in the treatment of pain. Lancet 1979;i:527-9.

41 Skoeld M, Gillberg L, Ohlsson O. Pain relief in myocardial infarction after continuous epidural morphine analgesia. $N$ Engl J Med 1985;312:630.

42 Blomberg $S$, Emanuelsson H, Ricksten S-E, Hjalmarson $\AA$. Thoracal epidural anesthesia in unstable angina pectoris [Abstract]. X World Congress of Cardiology, Washington, September 1986.

43 Chakravarty K, Tucker W, Rosen M, Vickers MD. Comparison of buprenorphine and pethidine given intravenously on demand to relieve postoperative pain. $\mathrm{Br}$ Med J 1979;ii:895-7.

44 Evans JM, McCarthy JP, Rosen M, Hogg MIJ. Apparatus for patient-controlled administration of intravenous narcotics during labour. Lancet 1976;i: 17-8.

45 Herlitz J, Richterova A, Bondestam E, Hjalmarson $\AA$, Holmberg $S$, Hovgren $C$. Chest pain in acute myocardial infarction. A descriptive study according to subjective assessment and morphine requirement. Clin Cardiol 1986;9:423-8. 